\title{
Pengembangan Sistem Informasi Layanan Pusat Karir dengan Memanfaatkan Peta Digital Mapbox
}

\author{
Kadek Ayu Putri Meydiana, Awalludiyah Ambarwati, Immah Inayati \\ Sistem Informasi, Ilmu Komputer, Universitas Narotama, \\ Jl. Arif Rahman Hakim No.51, Klampis Ngasem, Kec. Sukolilo, Surabaya, 60117, Indonesia \\ kadek@fik.narotama.ac.id
}

\begin{abstract}
Abstrak
Studi ini membahas pengembangan aplikasi layanan pusat karir dengan memanfaatkan platform Mapbox untuk menampilkan informasi tentang penyebaran alumni. Dari hasil wawancara terdapat aplikasi yang sudah ada tetapi belum dapat berjalan optimal, terutama dalam memberikan informasi tentang penyebaran lulusan Stikom Surabaya. Fokus utama dari penelitian ini adalah bagaimana menyajikan penyebaran alumni dalam bentuk peta digital, mendistribusikan kuesioner secara digital, dan menyajikan laporan yang informatif. Pengembangan aplikasi ini menggunakan metode Prototyping dan framework CodeIgniter versi 3.1.0 dengan PHP. Penelitian ini akan menghasilkan aplikasi Tracer Study dengan memanfaatkan peta digital MapBox untuk menampilkan peta penyebaran alumni. Dengan penelitian ini dapat membantu SCC dalam memberikan informasi tentang penyebaran alumni dan mendukung pengambilan keputusan di tingkat struktural, dekan fakultas dan pimpinan Stikom Surabaya.
\end{abstract}

Kata Kunci: Tracer study, MapBox, Metode prototyping, Stikom Career Center Surabaya

\section{Pendahuluan}

Sebuah perguruan tinggi perlu memiliki aplikasi Tracer Study karena memerlukan umpan balik dari alumninya untuk meningkatkan sistem dan manajemen pendidikan. Masukan, kondisi, dan motivasi ini menentukan perguruan tinggi untuk menerapkan sistem dan manajemen pendidikan dengan pola atau proses belajar mengajar, penelitian, praktik, kurikulum, lokakarya, laboratorium, studio atau penelitian. Institut Bisnis dan Informatika Stikom Surabaya, atau sering disebut Stikom Surabaya, mendirikan departemen yang disebut Stikom Career Center (SCC). SCC adalah pusat pengembangan karir, yang berada di bawah Wakil Ketua Rektor Bidang Kemahasiswaan dan Alumni. Dari hasil wawancara langsung ke SCC, saat ini ada aplikasi layanan pusat karir yang digunakan termasuk aplikasi Tracer Study. Namun fungsi dari aplikasi tracer study ini masih belum berjalan secara optimal, karena ada beberapa fitur yang seharusnya dapat memfasilitasi penggunaan aplikasi terkait penyebaran kuesioner dan pengolahan data kuesioner yang belum disajikan secara informatif.

Faktor-faktor yang membuat aplikasi belum dapat berjalan secara optimal antara lain, informasi terkait pengisian kuesioner masih dilakukan secara manual, aplikasi masih statis, pemrosesan laporan hasil pengolahan kuesioner tidak lengkap. Ini membuat karyawan SCC kesulitan dalam menyajikan data kuesioner. Terutama saat memetakan penyebaran lulusan Stikom Surabaya. Data tentang penyebaran lulusan Stikom Surabaya sangat penting bagi SCC untuk membangun jaringan antara alumni Stikom Surabaya serta untuk mendukung pengambilan keputusan di tingkat struktural (kepala seksi) serta Dekan fakultas dan para pemimpin Stikom Surabaya. Selain itu, data tentang penyebaran alumni juga merupakan laporan rutin yang diminta oleh DIKTI.

Penelitian ini akan menghasilkan aplikasi layanan pusat karir yang mencakup aplikasi Tracer Study dengan memanfaatkan peta digital MapBox untuk menampilkan peta penyebaran alumni. Mapbox adalah 'platform pemetaan sumber terbuka untuk peta desain khusus', yang telah tersedia sejak 2010 (Kent dan Vujakovic, 2017). Diharapkan penelitian ini dapat membantu SCC dalam memberikan 
informasi tentang kegiatan alumni dan dapat digunakan sebagai bahan evaluasi untuk perubahan kurikulum bagi mereka yang membutuhkan.

\section{Metodologi}

Diagram model prototyping pada gambar 1 dimulai pada tahap komunikasi antara pengembang dan pengguna untuk mendapatkan persyaratan sistem yang diketahui pengguna. Kemudian, perencanaan iterasi dilakukan untuk membuat prototipe dengan cepat dan pemodelan dalam bentuk desain cepat dalam bentuk desain antarmuka atau format tampilan.

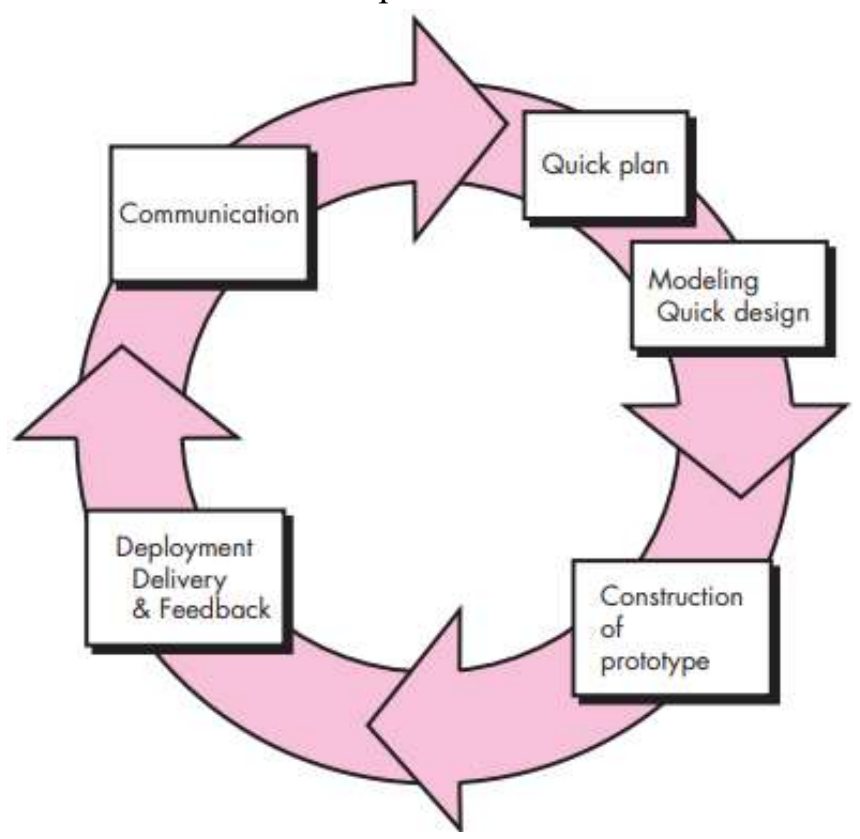

Gambar 1. Model prototyping (Pressman, 2010)

Desain cepat ini adalah dasar untuk membangun prototipe yang kemudian diberikan kepada pengguna untuk dievaluasi dan mendapatkan umpan balik untuk meningkatkan analisis kebutuhan. Dikatakan iterasi jika pengembang membuat perbaikan prototipe (Pressman, 2010). Pada bagian ini metode penelitian yang digunakan dalam penelitian ini mengadaptasi metode Prototipe. Ada beberapa langkah yang digunakan dalam penelitian ini adalah komunikasi, rencana cepat dan pemodelan desain cepat, prototipe konstruksi, pengembangan sistem, dan pengiriman penyebaran dan umpan balik.

Pada gambar 2 menggambarkan diagram alur yang digunakan dalam metodologi penelitian. Ada tahap awal, yaitu perencanaan. Tahap selanjutnya dibagi menjadi empat iterasi, yaitu, iterasi pertama dilakukan untuk menghasilkan gambar prototipe dan desain antarmuka tahap satu; iterasi kedua menghasilkan prototipe tahap kedua dan desain antarmuka tahap dua; iterasi ketiga menggambarkan pembuatan program tahap pertama dan evaluasi program; sedangkan iterasi keempat menghasilkan program yang sesuai dengan apa yang diharapkan pengguna. setelah tahap empat iterasi proses percobaan sistem dilakukan dan kemudian sistem diimplementasikan.

\subsection{Perencanaan (Planning)}

Tahap perencanaan merupakan tahap awal dalam penelitian. Ada beberapa hal yang ditentukan dalam tahap perencanaan ini, yaitu:

a. Menentukan masalah

Permasalahan merupakan kunci utama mengapa penelitian ini dibuat. Dalam proses perumusan masalah, dilakukan observasi untuk melihat keadaan SCC Surabaya secara langsung.

b. Menentukan ruang lingkup dan tujuan

Penentuan ruang lingkup ini dilakukan agar penelitian lebih terarah, sedangkan tujuan merupakan sasaran yang akan dicapai dalam penyusunan penelitian ini. 


\subsection{Komunikasi (Communication)}

Pada penelitian ini, dilakukan diskusi dan pengumpulan kebutuhan untuk mengetahui berbagai permasalahan yang terjadi di lapangan, sehingga dapat menentukan pokok-pokok permasalahan yang ada dengan menggunakan berbagai metode sebagai berikut:

a. Wawancara: pada tahap ini dilakukan wawancara kepada salah satu karyawan SCC untuk mengetahui kebutuhan sistem yang diinginkan dan proses bisnis yang berjalan.

b. Studi Pustaka: pada tahap ini dilakukan pencarian berbagai sumber terpercaya dalam studi pustaka untuk melengkapi dan menjadi referensi terhadap penelitian pengembangan sistem informasi layanan pusat karir.

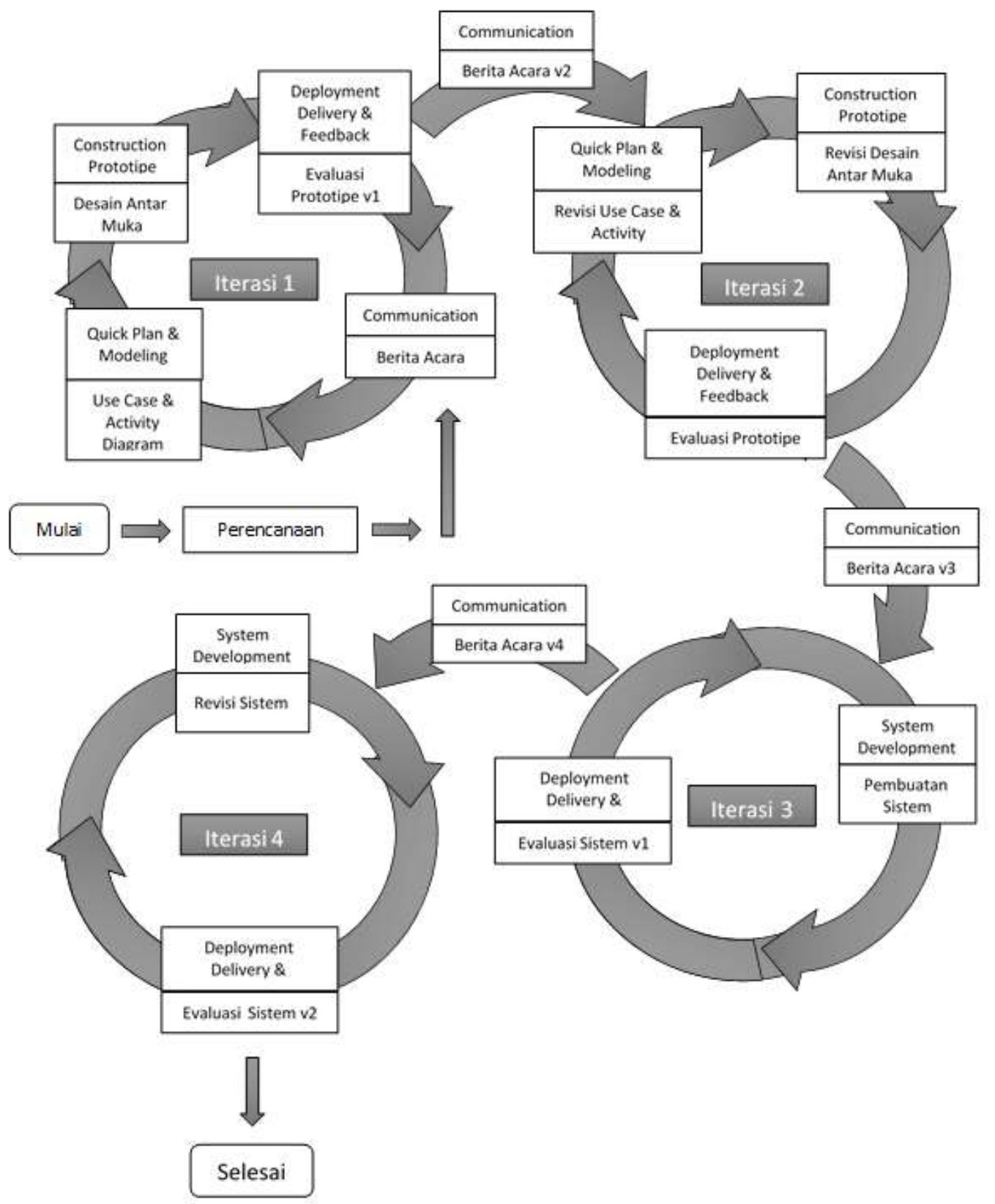

Gambar 2. Alur diagram metodologi penelitian

\subsection{Membangun Desain Secara Cepat (Quick Plan and Modeling)}

Pada tahapan membangun desain secara cepat dilakukan dengan menggunakan pemodelan UML (Unified Modeling Language). Permodelan UML yang digunakan adalah Use Case Diagram dan Activity Diagram. 


\subsection{Pembangunan Prototipe (Construction Prototype)}

Pada tahap ini pembuatan prototipe direncanakan dengan cepat dan pemodelan dalam bentuk rancangan cepat. Suatu rancangan cepat berfokus pada representasi semua aspek perangkat lunak yang akan terlihat oleh para pengguna akhir. Pembuatan rancangan antarmuka atau format tampilan dibuat dengan menggunakan aplikasi Enterprise Architect.

\subsection{Pembangunan Sistem (System Development)}

Pada tahap ini pembangunan sistem menggunakan Bootstrap Gentelela. Gentelella adalah template admin responsif yang dibuat dengan gaya flat. Pada tahap ini juga dilakukan pengkodean aplikasi. Pengkodean aplikasi menggunakan bahasa pemrograman PHP (Hypertext Preprocessor) dengan framework CodeIgniter, platform peta digital MapBox dan Sublime Text 3 editor. Peneliti juga menggunakan perangkat lunak basis data MySQL untuk mengolah data yang didapatkan.

\subsection{Penyerahan Sistem dan Umpan Balik (Deployment Delivery and Feedback)}

Tahapan ini mengevaluasi prototype ataupun sistem dengan melakukan diskusi kepada pihak SCC Stikom dan memperhalus analisis terhadap kebutuhan pengguna. Pada tahap ini juga dilakukan dokumentasi sebagai bahan lampiran pada laporan.

\section{Hasil dan Pembahasan}

\subsection{Iterasi Pertama}

Tahap iterasi pertama adalah tahapan model proses pertama dimana terdapat beberapa tahapan diantaranya adalah communication dengan hasil berupa berita acara, quick design and model dengan hasil berupa use case dan activity diagram, construction prototype dengan hasil berupa rancangan desain antarmuka secara cepat, deployment delivery and feedback dengan hasil berupa evaluasi dari seluruh tahapan yang dilakukan.

a. Use Case dan Activity Diagram

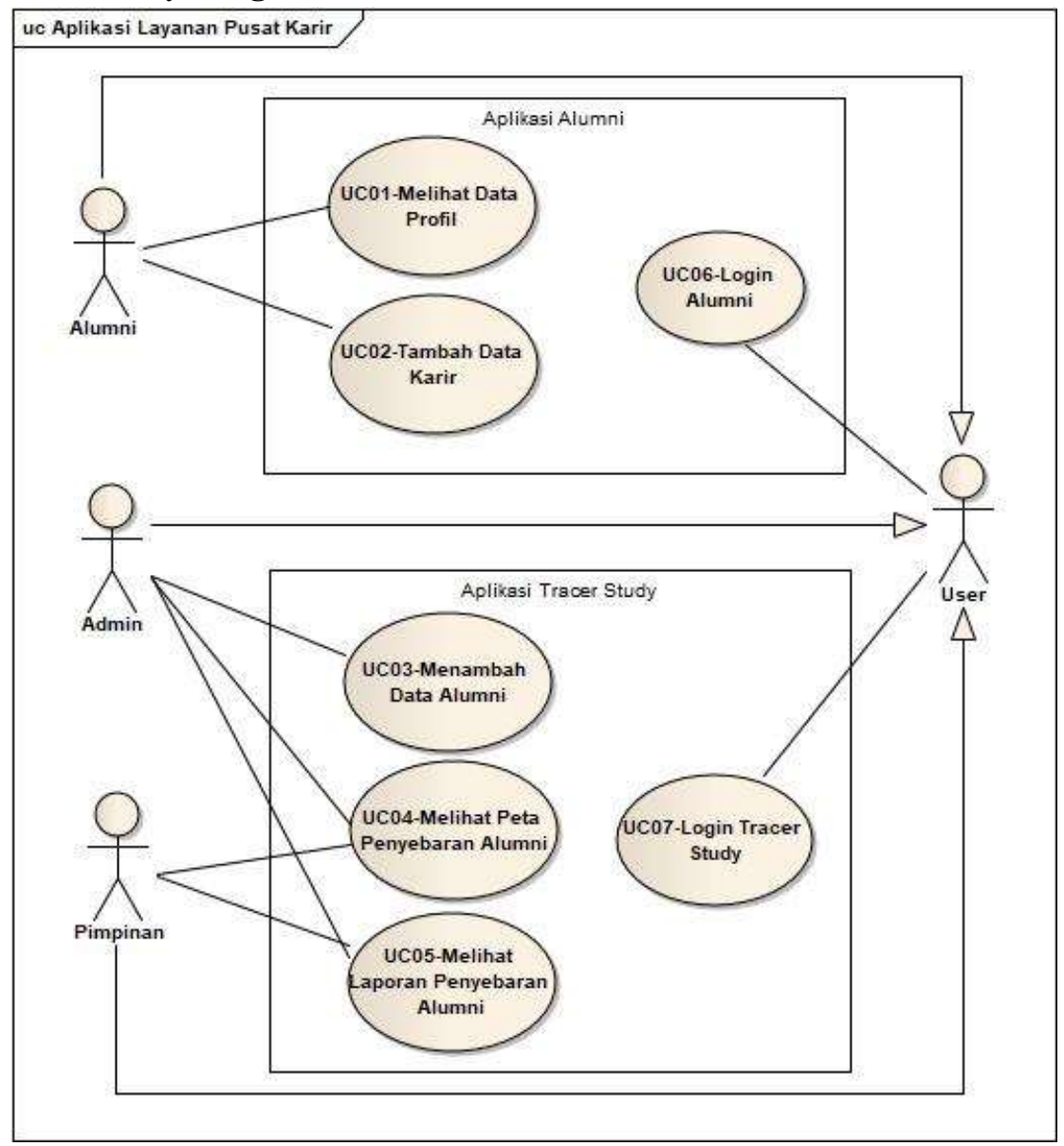

Gambar 3. Use Case Diagram Layanan Pusat Karir 
Use case merupakan gambaran aktivitas yang dapat dilakukan oleh sistem dan diterima oleh pengguna. Use case pada gambar 3 menggambarkan tentang aktivitas yang dapat dilakukan oleh User terhadap sistem layanan pusat karir. Pada use case ini terdapat 3 actor dan 7 Aktivitas. Gambar 4 menggambarkan diagram aktivitas untuk melihat peta penyebaran alumni oleh Pimpinan pada aplikasi Tracer Study. Dimulai pada pengguna pimpinan masuk ke menu maps lalu sistem akan menampilkan halaman peta penyebaran alumni. Pimpinan dapat klik pin untuk melihat informasi alumni yang ditampilkan oleh sistem.

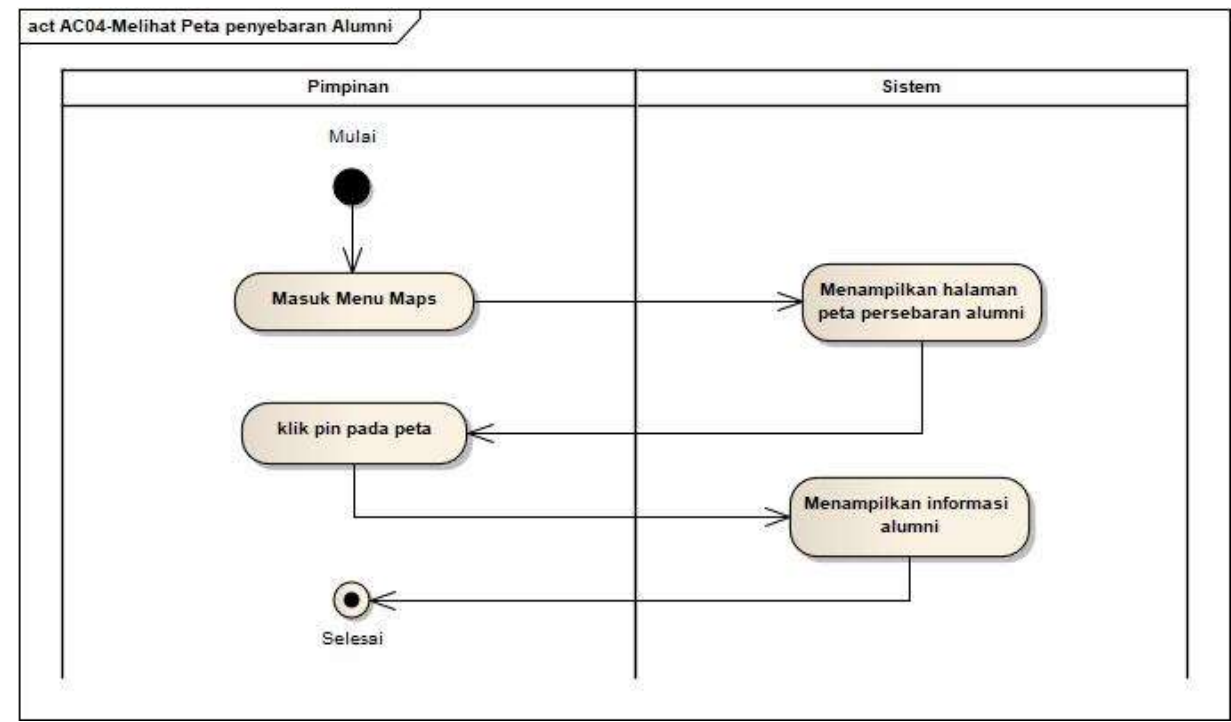

Gambar 4. Diagram aktivitas melihat peta penyebaran alumni

\section{b. Desain Antar Muka}

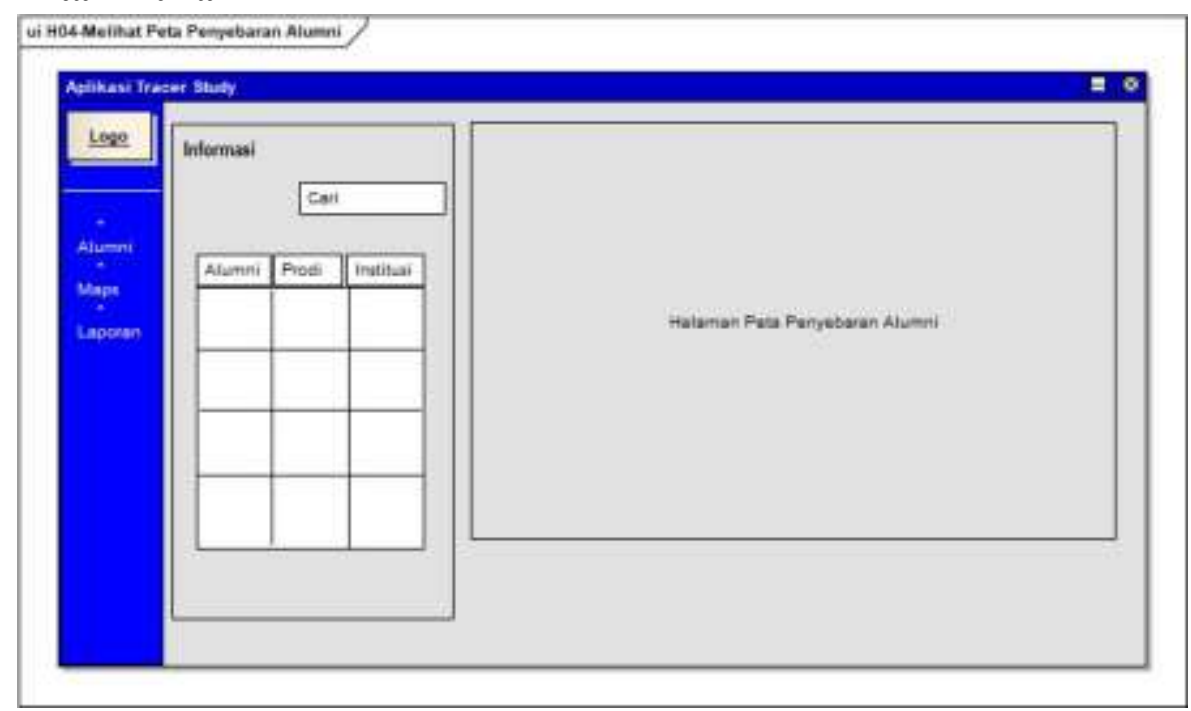

Gambar 5. Desain antar muka melihat peta penyebaran alumni

Pada gambar 5 menggambarkan desain antarmuka melihat peta penyebaran alumni oleh Pimpinan dan admin pada aplikasi Tracer Study. Pada halaman terdapat tabel data alumni yaitu alumni, prodi, dan institusi, textbox pencarian dan halaman peta. Halaman ini terdapat pada iterasi pertama sebagai desain antarmuka pertama yang dibuat.

\subsection{Iterasi Ke Dua}

Tahap iterasi kedua adalah tahapan model proses kedua (revisi dari tahapan iterasi pertama) dimana terdapat beberapa tahapan diantaranya adalah communication dengan hasil berita acara hasil wawancara kedua, quick design and model dengan hasil berupa use case dan activity diagram terbaru, construction prototype dengan hasil rancangan desain antarmuka terbaru, deployment delivery and feedback dengan hasil berupa evaluasi dari seluruh tahapan iterasi kedua. 


\section{a. Use Case dan Activity Diagram}

Use case merupakan gambaran aktivitas yang dapat dilakukan oleh sistem dan diterima oleh pengguna. Use case pada gambar 6 menggambarkan tentang aktivitas yang dapat dilakukan oleh User terhadap sistem layanan pusat karir. Pada use case ini terdapat 5 actor dan 12 Aktivitas.

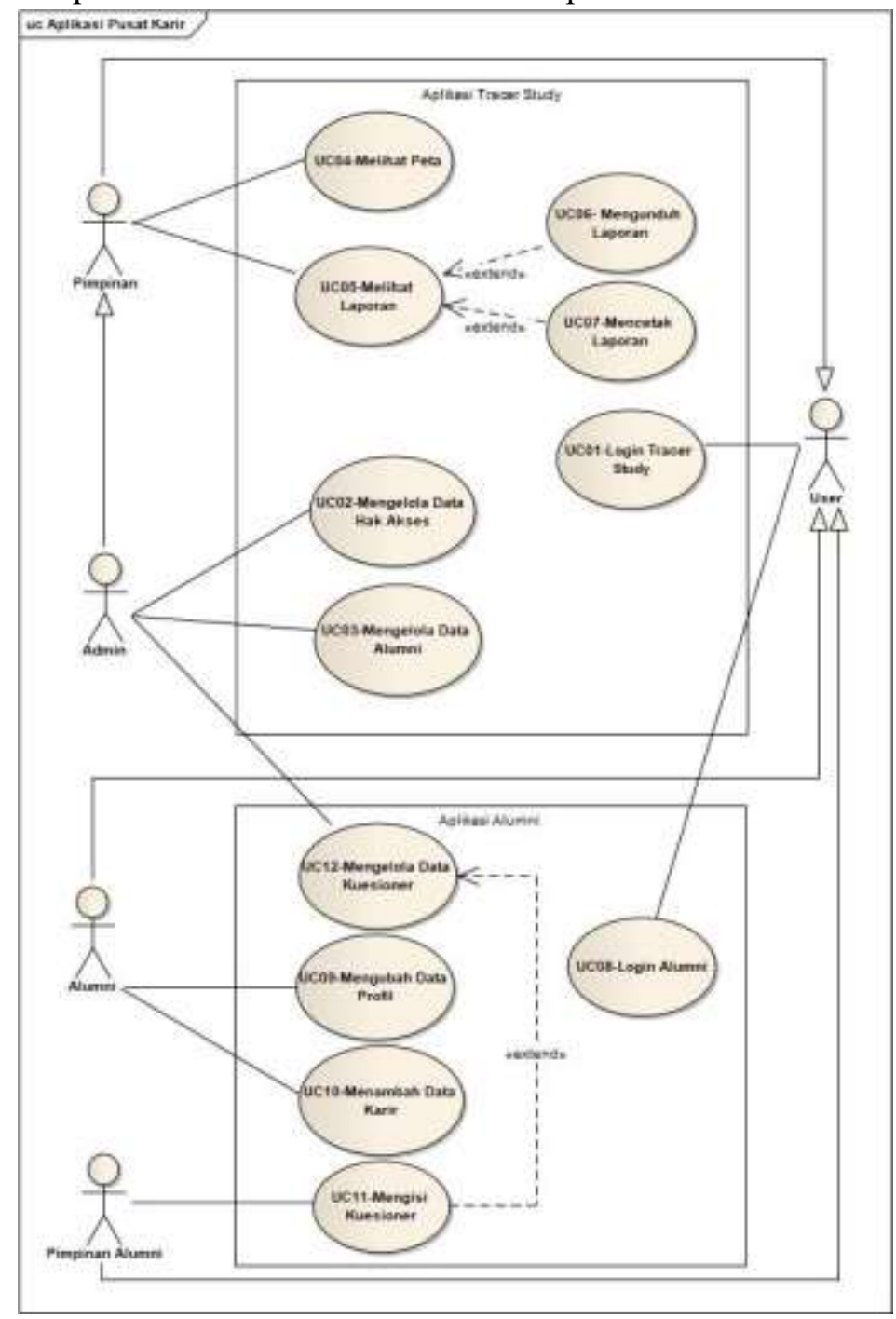

Gambar 6. Use Case Diagram Aplikasi Layanan Pusat Karir

Gambar 7 menggambarkan diagram aktivitas mengunduh laporan yang dilakukan oleh Pimpinan pada aplikasi Tracer Study. Pimpinan melakukan login lalu masuk ke menu report. Pimpinan dapat mengunduh laporan dengan berbagai format diantaranya, copy, CSV, Excel, dan PDF. Pimpinan dapat klik copy jika membutuhkan data untuk di tempel pada dokumen lain atau memilih CSV, Excel, dan PDF sebagai dokumen dengan format pengolah data. Secara otomatis sistem akan mengunduh laporan dan menyimpan kedalam media penyimpanan pengguna. 


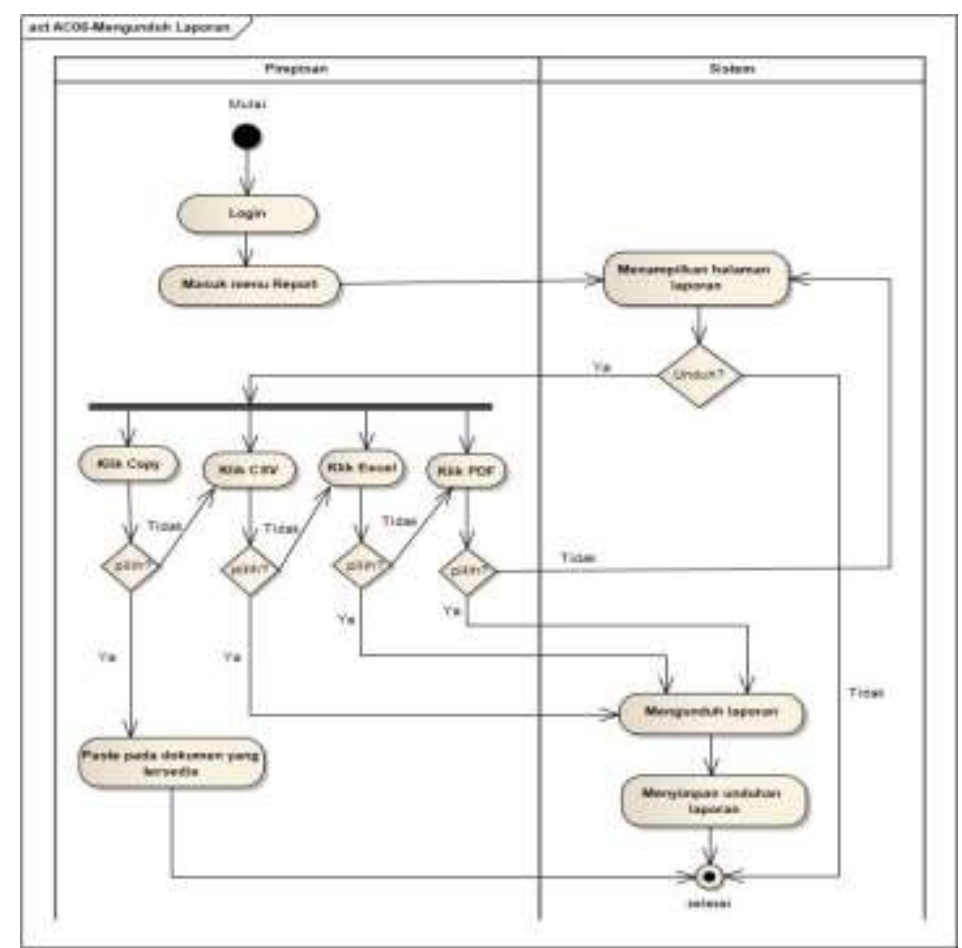

Gambar 7. Diagram Aktivitas Mengunduh Laporan

\section{b. Desain Antar Muka}

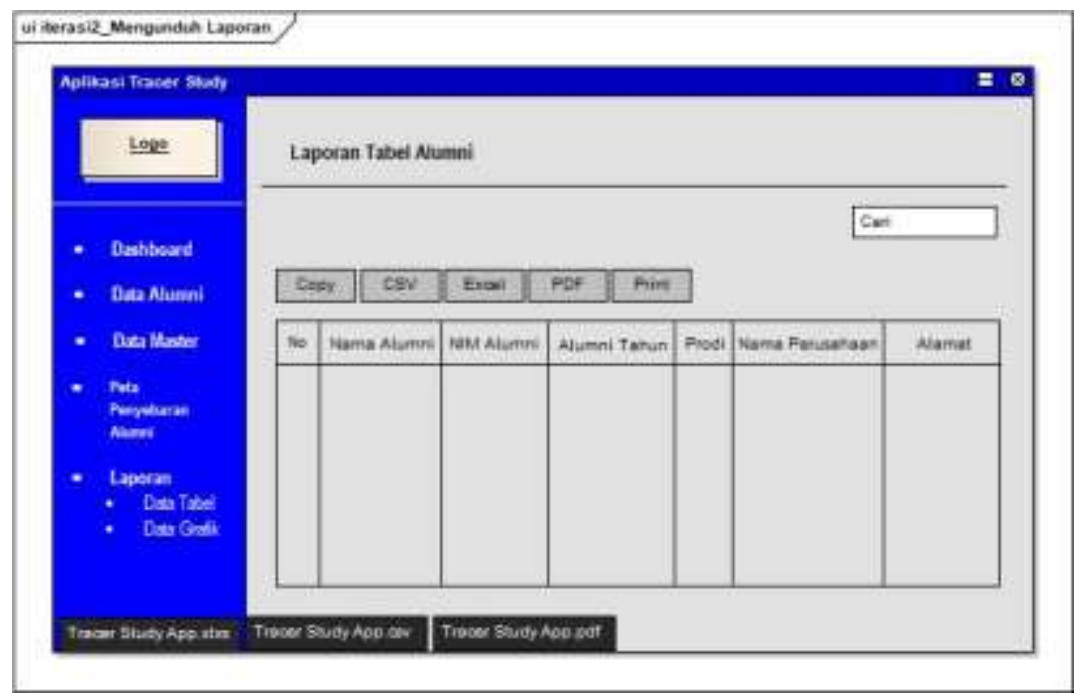

Gambar 8. Desain antar muka mengunduh laporan

Desain antarmuka mengunduh laporan penyebaran alumni pada aplikasi Tracer Study terdapat pada Gambar 8. Desain menggambarkan logo Stikom pada bagian kiri atas halaman, daftar nama menu pada sisi kiri, dan halaman laporan data penyebaran alumni dalam bentuk tabel, dan terdapat tombol unduh pada bagian atas tabel serta textbox pencarian untuk memudahkan pencarian daftar nama alumni yang akan dicetak. User yang dapat melihat laporan ini adalah Admin dan Pimpinan.

\subsection{Iterasi Ke Tiga}

Pada tahap ini dilakukan pembangunan sistem dari hasil evalusi prototipe pada tahapan iterasi kedua.

\section{a. Pembuatan Sistem}

Pada gambar 9 ini menggambarkan halaman peta penyebaran alumni pada aplikasi Tracer Study. Pada halaman ini pengguna dapat melihat penyebaran alumni di Indonesia hingga di luar negeri. Selain 
itu pengguna juga dapat melakukan klik pada tabel atau menekan pin pada peta untuk melihat detail lokasi alumni. Pengguna yang dapat melihat peta penyebaran ini adalah Admin dan Pimpinan.

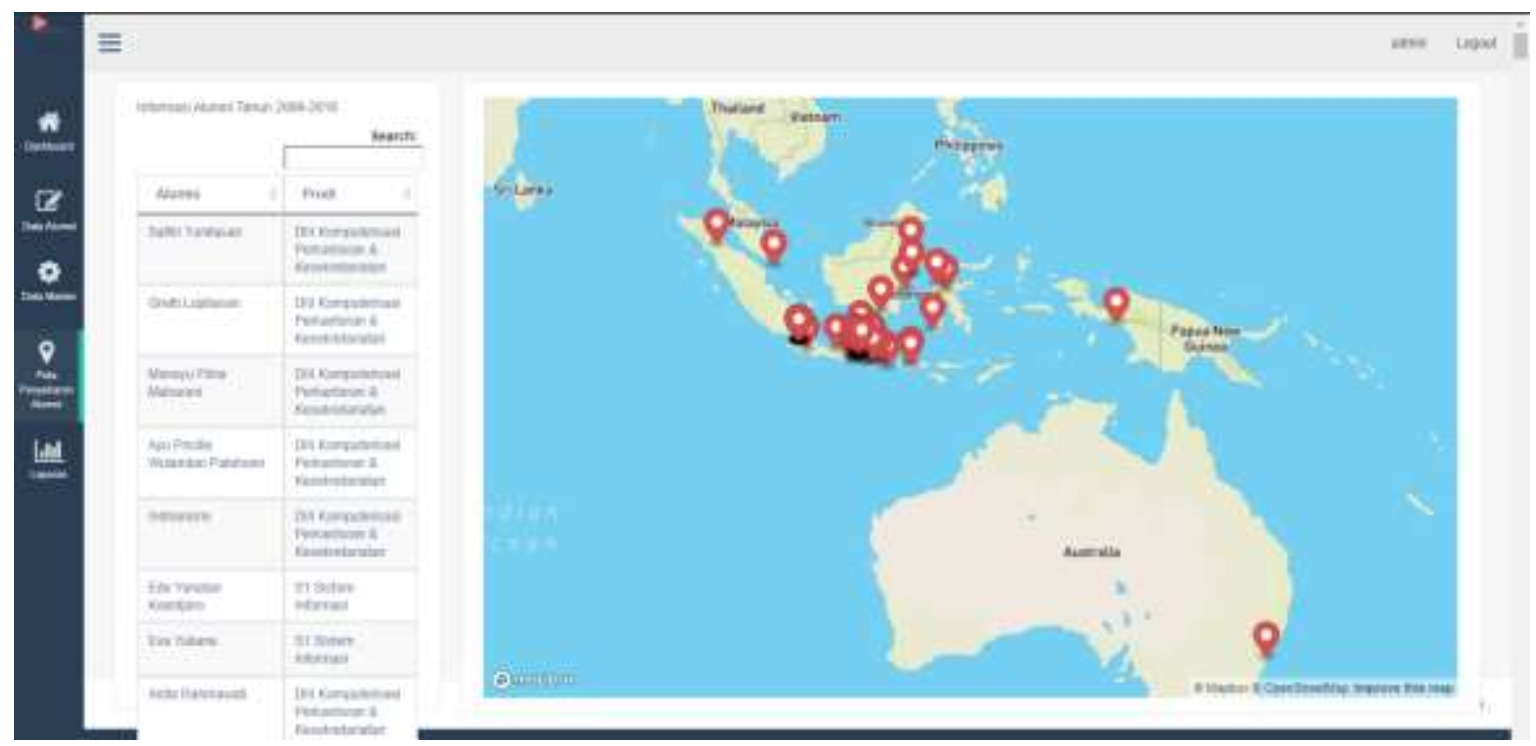

Gambar 9. Menu peta penyebaran alumni Aplikasi Tracer Study

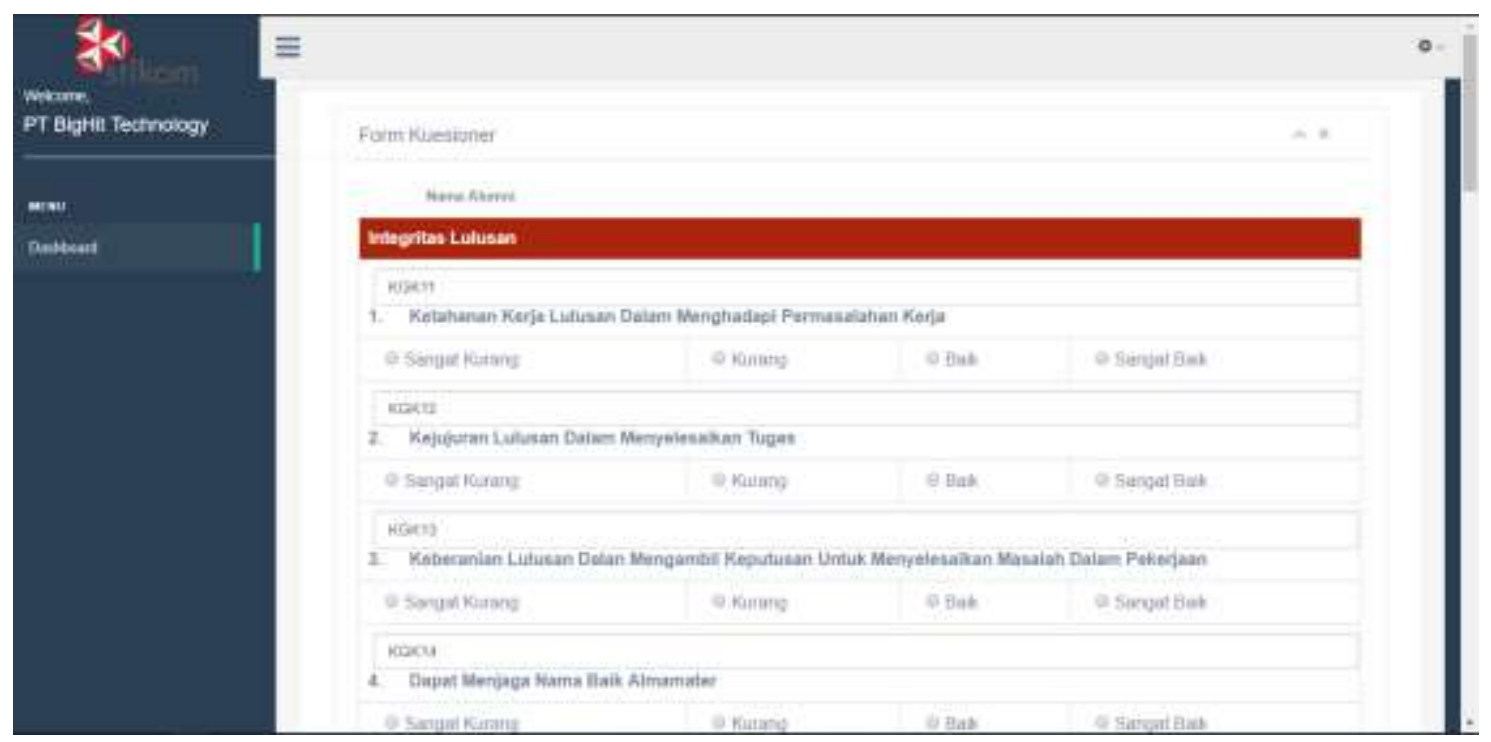

Gambar 10. Menu isi kuesioner aplikasi alumni

Pada gambar 10 ini menggambarkan halaman isi kuesioner pada aplikasi Alumni. Pimpinan alumni akan diberikan username dan password yang akan dikirimkan melalui email oleh pihak SCC untuk dapat masuk ke dalam aplikasi mengisi kuesioner. Pada halaman ini pengguna Pimpinan Alumni dapat mengisi kuesioner dengan memilih nama alumni terlebih dahulu, setelah selesai mengisi kuesioner maka pimpinan alumni dapat menekan tombol simpan untuk menyimpan hasil kuesioner ke dalam database.

Gambar 11 ini menggambarkan halaman menu laporan data diagram lingkaran pada aplikasi Tracer Study. Pada halaman ini pengguna Admin dan Pimpinan dapat melihat laporan diagram dari data penyebaran alumni. Laporan ini diperoleh berdasar alamat perusahaan tempat alumni bekerja sehingga menghasilkan informasi data alumni per-negara, per-provinsi, dan per-kota. Selain itu data program studi dan tahun lulus alumni juga menghasilkan laporan alumni per-prodi dan alumni per-tahun lulus. Dalam keseluruhan data alumni dapat diperolah laporan perbandingan alumni yang bekerja maupun tidak. 


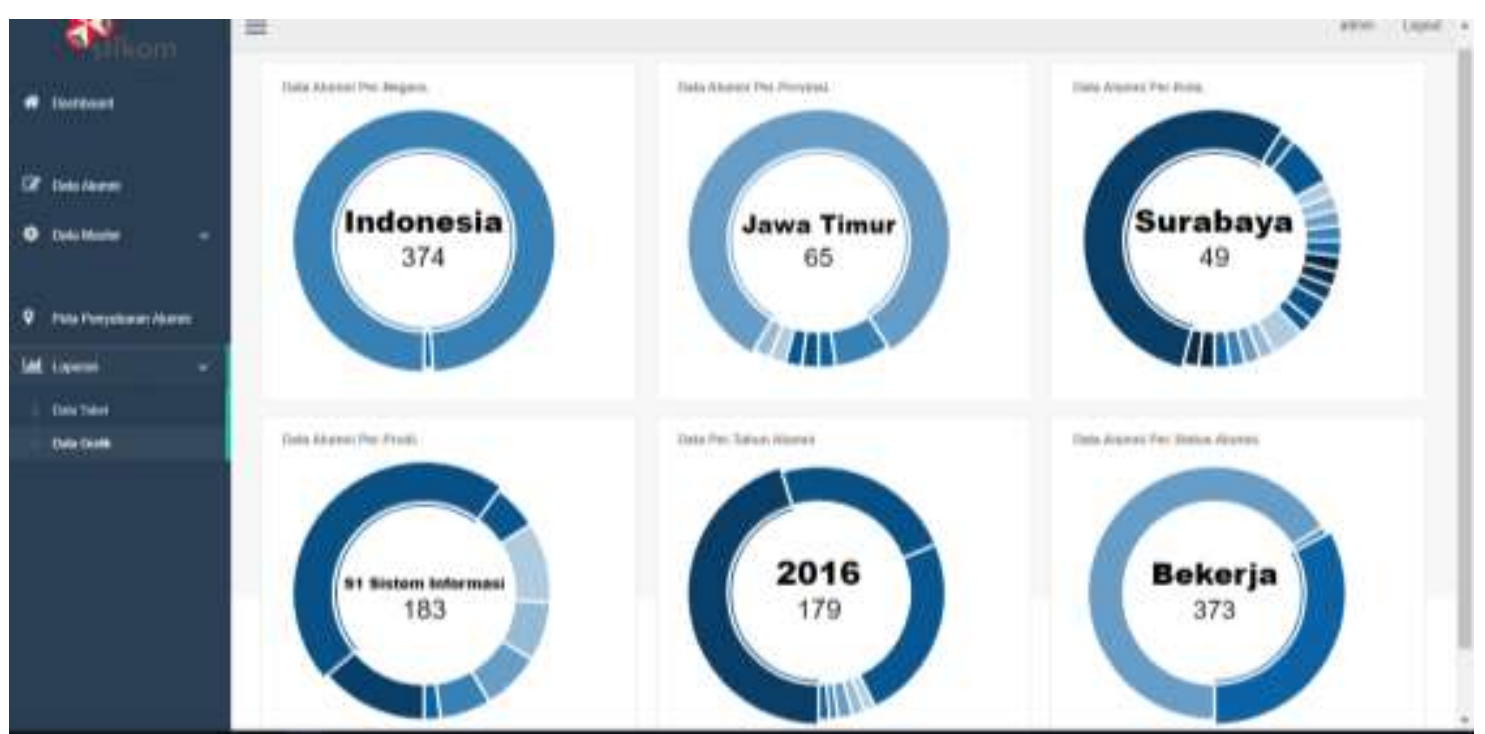

Gambar 11. Menu laporan data grafik Aplikasi Tracer Study

\section{b. Evaluasi Sistem}

Setelah selesai membangun sistem, maka dilakukan evaluasi sistem. Pada tahap ini diperoleh perubahan-perubahan pada sistem sebelumnya hingga dapat memenuhi kebutuhan pengguna.

\subsection{Iterasi Ke Empat}

Pada tahap ini dilakukan pembangunan sistem dari hasil evalusi sistem pada tahapan iterasi ke-tiga. Tahap ini menghasilkan 1 halaman sistem yang telah ditambah agar sesuai dengan kebutuhan pengguna.

a. Revisi Sistem

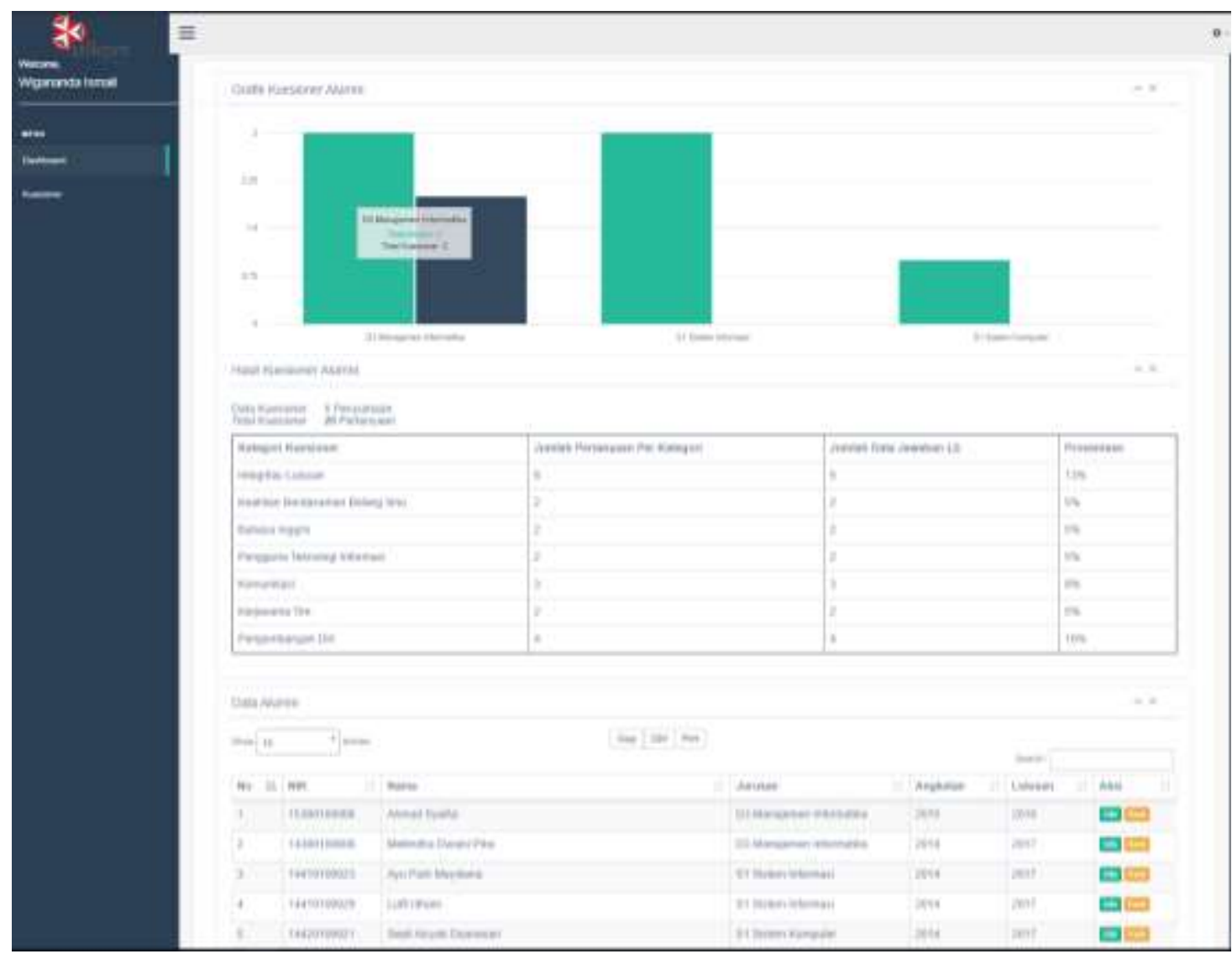

Gambar 12. Halaman dashboard Aplikasi Alumni 
Pada gambar 12 ini menggambarkan halaman dashboard pada aplikasi Alumni. Pada halaman ini pengguna dapat melihat laporan diagram batang dan tabel perhitungan hasil kuesioner pada setiap kategori soal. Pada bagian bawah perhitungan hasil kuesioner terdapat data tabel alumni yang dapat melihat info dan karir setiap alumni.

\section{b. Evaluasi Sistem}

Pada tahap ini diperoleh hasil dan penyelesaian dari proses iterasi ke-empat. Perubahan sistem yang terjadi adalah adanya penambahan menu dashboard untuk User Admin pada aplikasi Alumni.

\section{Kesimpulan dan Saran}

Hasil dari penelitian pengembangan aplikasi layanan pusat karir dengan menggunakan platform peta digital adalah pertama, aplikasi Tracer Study mampu menyajikan peta penyebaran alumni Stikom di seluruh dunia dengan default tampilan peta negara Indonesia; kedua, aplikasi Alumni mampu menyajikan halaman pengisian kuesioner kepada responden pengguna lulusan secara digital; ketiga, aplikasi Tracer Study dan Alumni terdapat halaman laporan penyebaran alumni dalam bentuk diagram lingkaran dan laporan tabel yang dapat diunduh sesuai format yang dibutuhkan.

Saran yang dapat diberikan untuk perbaikan dan perkembangan penelitian ini adalah data alamat perusahaan alumni pada aplikasi Tracer Study untuk penyebaran alumni dengan peta digital sebaiknya dapat dibuat otomatis tanpa perlu masukan dari admin. Selain itu perlu penambahan menu kuesioner untuk pengguna alumni sebagai data update alumni setelah 2 tahun lulus dari Stikom Surabaya.

\section{Ucapan Terima Kasih}

Pada kesempatan ini penulis mengucapkan terima kasih kepada Ibu Immah Inayati dan Ibu Awalludiyah Ambarwati yang memberikan banyak bimbingan dan dukungan dalam membantu persiapan penelitian ini. Selain itu penulis juga mengucapkan terima kasih pada BTS yang telah memberikan motivasi melalui karya lagu sehingga penulis antusias dalam melakukan penelitian ini serta semua pihak yang ada di Departemen SCC Surabaya.

\section{Daftar Pustaka}

Fitriani, L., Tresnawati, D., dan Rahayu, S. (2018). Design of geographic information system for tracer study. IOP Conf. Ser. Mater. Sci. Eng. 434, 012064. https://doi.org/10.1088/1757899X/434/1/012064

Kent, A. J. dan Vujakovic, P. (2017). The Routledge Handbook of Mapping and Cartography. Routledge.

Pressman, R. S. (2010). Software engineering: a practitioner's approach, 7. ed. ed. McGraw-Hill/Higher Education, Boston, Mass.

STIKOM CAREER CENTER SURABAYA [WWW Document], n.d. . STIKOM Career Cent. Surabaya. [online]. http://scc.stikom.edu/tentang_kami.php (Diakses 17 Maret 2019). 